\title{
PERFIL SENSORIAL DINÂMICO E ESTUDOS COM CONSUMIDORES DE SORVETE DE BAIXA CALORIA COM MANGA LIOFILIZADA
}

\section{Amanda M. Macedo*, Helena M. A. Bolini.}

\section{Resumo}

O objetivo do presente projeto foi elaborar seis diferentes formulações de sorvete com manga liofilizada, adoçado com sacarose e cinco diferentes edulcorantes (sucralose, xilitol, estévia RebA 95\%, estévia RebA 97\% e estévia RebM em mesma doçura equivalente) realizar estudos com consumidores de sorvete em relação à aceitação, intenção de compra, check-all-that-apply e análise dinâmica computadorizada Temporal Dominance Sensations (TDS). A análise de aceitação foi realizada por um grupo de 120 consumidores representativos do grupo alvo que registraram as respostas em escala hedônica não estruturada de $9 \mathrm{~cm}$. Os dados de aceitação foram analisados por ANOVA, testes de médias de Tukey $(p<0.05)$ e análise estatística multivariada de Mapa de Interno de Preferência. Os dados de CATA foram analisados por análise de correspondência. Os sorvetes adoçados com sacarose, xilitol e sucralose obtiveram maior preferência, e os demais não apresentaram rejeição. Os resultados obtidos originaram direcionadores de preferência para sorvetes de manga de baixa caloria, gerando informações importantes para as indústrias de alimentos, especialmente de sorvetes e produtos lácteos.

\section{Palavras-chave:}

Perfil Sensorial Dinâmico, Manga Liofilizada, Testes Afetivos.

\section{Introdução}

O presente projeto teve por finalidade avaliar à aceitação e perfis sensoriais de sorvete com substitutos da sacarose, estudo de grande interesse para as áreas da saúde e tecnologia de alimentos. Isso porque contribui para a verificação de possíveis diferenças nas características sensoriais dos produtos, proporcionadas pela adição dos edulcorantes no sistema em questão, como também para a verificação de quais são os edulcorantes de maior aceitação aplicados no produto do mercado, avaliando assim à importância do edulcorante na aceitação.

\section{Resultados e Discussão}

Foram realizados estudos de aceitação das amostras em relação à aparência, aroma, sabor, textura e impressão global. As amostras foram servidas aos provadores através de apresentação monádica em copos descartáveis devidamente codificados. As análises foram realizadas por uma equipe composta por 120 consumidores representativos do público alvo, utilizando escala hedônica não estruturada de nove centímetros. Os resultados acerca da impressão global, mapa interno de preferência e CTA dos 6 sorvetes estão ilustrados na figura abaixo:

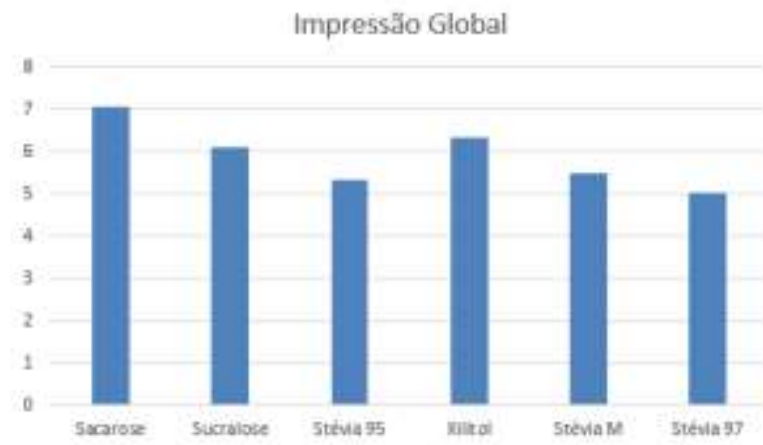

Figura 1. Médias de impressão global de cada amostra

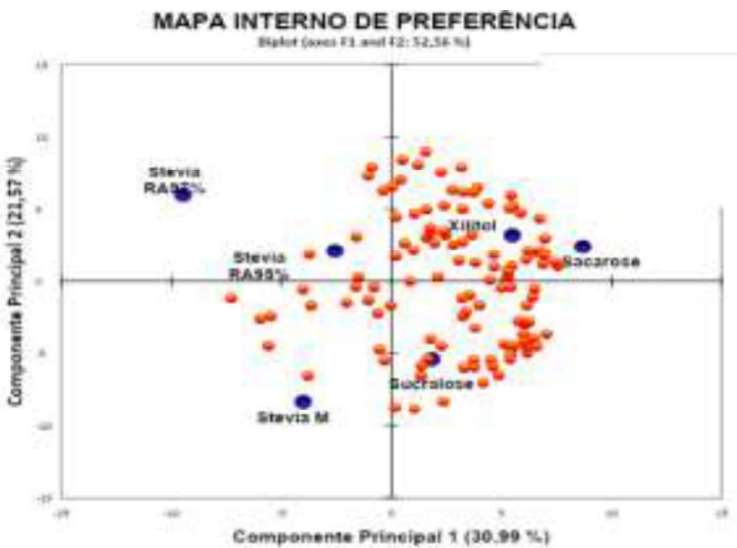

Figura 2. Mapa interno de preferência CORRESPONDENCE ANALYSIS CHECK-ALL-THAT-APPLY

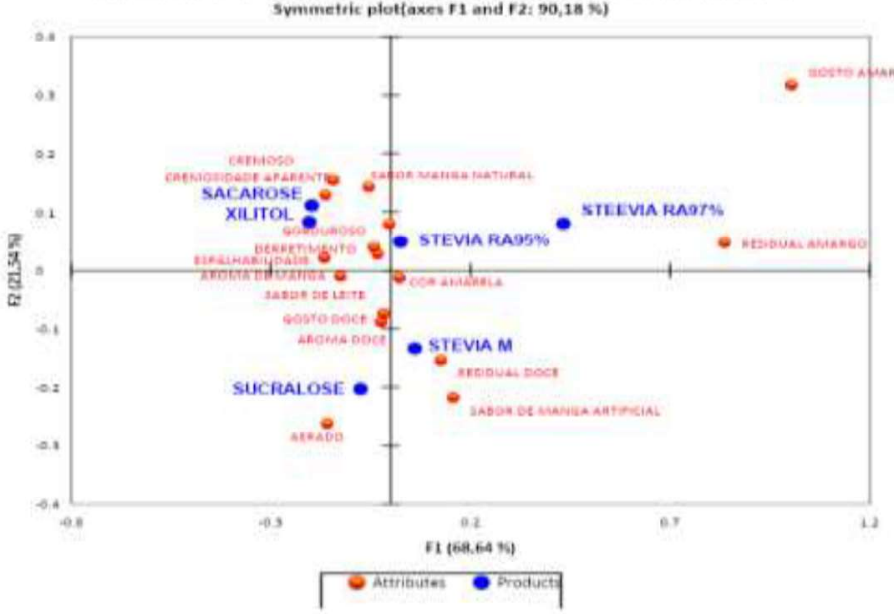

Figura 3. Resultado do CTA (Check All That Apply)

\section{Conclusões}

A partir da verificação dos resultados, por meio da análise de variância (ANOVA), testes de media de Tukey, além dos histogramas de distribuição das notas dadas em relação à escala hedônica e análise estatística multivariada Mapa Interno de Preferência foi possível avaliar que a amostra de xilitol pode ser um possível substituinte para a sacarose. 